\title{
Constructing the Olympic Dream: A Future Perfect Strategy of Project Management
}

\author{
Tyrone S. Pitsis • Stewart R. Clegg • Marton Marosszeky • Thekla Rura-Polley \\ School of Management, University of Technology, Sydney, Broadway NSW 2007, Sydney, Australia \\ School of Management, University of Technology, Sydney, Broadway NSW 2007, Sydney, Australia \\ School of the Built Environment, University of New South Wales, Sydney NSW 2033, Sydney, Australia \\ School of Management, University of Technology, Sydney, Broadway NSW 2007, Sydney, Australia \\ tyrone.pitsis@uts.edu.au・s.clegg@uts.edu.au・m.marosszeky@unsw.edu.au・thekla.rura.polley@uts.edu.au
}

\begin{abstract}
In this paper we investigate a uniquely complex organizational context-that of the fast-tracked large-scale project management of a significant piece of Sydney 2000 Olympic infrastructure, which we researched in terms of its management through the "future perfect." In a grounded analysis we resolved to track how the future perfect developed in the life of one large, complex project whose uniqueness meant that it was unable to be strategically planned in advance. We tracked the use of what we term "future perfect strategy" through analysis of data collected both in leadership meetings of the directing agency, "PALT"-Project Alliance Leadership Team-as well as in individual interviews that we conducted in and around the project, and through analysis of media coverage. Overall, the project was a success, but some problems arose along the way to completion. Largely, these were focused on issues of social rather than technical construction-something even the most strategic of plans cannot account for. As well as identifying some of the specific mechanisms for encouraging future perfect strategy that were used in the project, including encouraging "strange conversations," "playing end games," "workshopping," and "projecting feelings, concerns and issues," we also suggest some ways that the social construction issues might be handled in the future.

(Interorganizational Collaboration; Project Management; Strategic Management; Future Perfect)
\end{abstract}

\section{The Future Perfect}

How do we deal with it now to avoid it later?

This question was put by one of the Project Alliance Leadership Team members during the project that frames our reflections in this paper. In many respects, it is a quintessential management question-how to make the uncertainty attached to the future something that can be dealt with in advance of it occurring? There are many, equally quintessential, strategic management answersbut none of them frame this paper. Instead, we introduce the reader to a new conception, that of managing through the future perfect, an approach to strategic management that occurred in a context where planning was practically impossible. Out of this adversity-in which to plan was a luxury that could not be affordedemerged a new approach to strategic management.

The concept of the future perfect is one that, for us, is rooted in the philosophy of Alfred Schütz (1967, p. 61), who defined the future perfect as the cognitive process by which an "....actor projects his actions as if it were already over and done with and lying in the past...Strangely enough, therefore, because it is pictured as completed, the planned act bears the temporal character of pastness.... The fact that it is thus pictured as if it were simultaneously past and future can be taken care of by saying that it is thought of in the future perfect tense." While many researchers and authors have adopted Schutz's notion of the future perfect (see Langlois 1990, Langlois and Csontos 1993, Davis 1987, Hogarth 1987, Bandrowski 1990, LeonardBarton 1992, Schilling 1998, Rollier and Turner 1994, Bavelas 1973, Boland 1984), it was Weick (1969, 1995, 2000) who did most to make Schütz known amongst management theorists. Weick's conception of enactment, for instance, relies on the creation of meaning through action oriented to the future perfect (Schütz 1967). In the future perfect, the forward-looking projection of ends is combined with a visualization of the means by which that projected future may be accomplished (Weick 1979, p. 198). In this paper we extend Schütz's key concept from analysis in decision making, urban planning, and organization theory (Petranker 2000; Weick 1969, 1979, 2000) to project management.

It is important to differentiate the future perfect from some other common strategic conceptions that are 
temporally sophisticated, such as the concept of strategic thinking (Ohmae 1993, Rowe et al. 1986, Lenz 1987). Strategic thinking has been presented as a dynamic approach, one that addresses planning's overly rational orientation and its obsession with extrapolation from past data (Buttery et al. 1999). Scenario planning has also been advocated as a way of achieving more creative strategic thinking (Van Der Heijden 1996, Ringland 1998). Ringland (1998, p. 2) has defined scenario planning as that part of strategic planning which relates to tools and technologies for managing the uncertainties of the future. Use of future perfect strategy differs significantly from scenario planning. It combines forwardlooking projection of ends with a visualization of the means by which that projected future may be accomplished, as an emergent rather than explicitly scripted strategy. Scenario planning has been explicitly developed for situations of high uncertainty such as work in the oil industry, where most of the work is done at the planning stages of the project, to instill a vision of what the future "may" look like in order to create mental maps of how one might deal with variation if it occurs. In one sense, these approaches share some of the rationality of the planning models they criticize. Although they do not extrapolate from past data, they extrapolate from past expectations grounded in extensive practice under "business as usual" conditions. Moreover, they tend to be deeply embedded in competitive frameworks for analysis, rather than those that are collaborative.

By projecting as yet nonexistent phenomena into an imagined future, construction projects, in general, offer a prime site for research in the complex organization of interorganizational collaboration. Interorganizational collaboration has been defined as "[a] process through which parties who see different aspects of a problem can constructively explore their differences and search for solutions that go beyond their own limited vision of what is possible (Gray 1989, p. 5). It has been argued that collaboration might operate as a strategic tool for gaining efficiency and flexibility in times of rapid change (Westley and Vredenburg 1991, p. 66). Collaboration produces new capabilities for organizations that they could not achieve alone; moreover, it aids organizations in innovating solutions beyond an individual organization's presently bounded rationality, as well as being a way of spreading risk and pooling resources. Typically, such projects achieve high rates of failure in meeting stated objectives, leading some to question the viability of alliancing (see Koza and Lewin 1999, Flyvbjerg et al. 2002). Consequently, how interorganizational collaborative quality is achieved is a significant area for research. It was in seeking to understand, describe, and analyze how collaborative quality was able to occur in a project that we began to investigate the future perfect as a strategy. ${ }^{1}$ Typically, contractual policing, litigation, and arbitration, ${ }^{2}$ especially in situations of multiple actors and interests, characterize projects. We discovered a project where dysfunctional organizational characteristics did not apply, because of innovative interorganizational strategic leadership. For Hitt (1998), effective strategic leaders need to create new managerial mindsets to avoid the failures of the past. We argue that future perfect strategy provides a means for doing so.

The structure of the paper is as follows. First, we identify and elaborate some of the detail of the project. Second, we outline the methods that we used in researching the project. Third, we move to a discussion of some of the ways in which the actors in the project organization used future perfect thinking in their everyday management. Fourth, we discuss some of the anticipated and unanticipated outcomes that they achieved through doing so, before moving to some conclusions.

\section{The Project}

\section{Fast-Tracking for the Olympics}

A decision to undertake a major project in the run up to the Sydney 2000 Olympics was taken as a part of the NSW Government Waterways Project in May 1997, designed to clean up NSW rivers, beaches, and waterways. Cleaning up the waters of Sydney Harbour was seen as a priority for the Olympics in 2000, given that the "eyes" of the world would be on the city in just over three years. ${ }^{3}$ The proposal sought to capture sewage overflows that occurred during Sydney's subtropical storms, when stormwater backs up the sewage system and overflows into the harbour, bringing in not only raw sewage but also street detritus such as litter, syringes, and dog faeces. The main detail of the project was to build approximately 20 kilometers of tunnel in the sandstone under the very affluent areas north of Sydney Harbour.

The project was unique on a number of counts: in its symbolic and social impact; as a major piece of Sydney Olympics infrastructure; in its innovative prefiguring of an increasing use of public/private partnerships; and in the mode of its delivery, without any prior specification of methods, machinery, and environmental conditions through detailed prior planning. A global indicative budget was determined for the project, with the possibility of performance on the budgetand a number of other key performance indicators that we will encounter shortly-being linked to returns to the parties involved in the project. If the budget was 
saved, the partners made money; if it was exceeded, they lost money. An additional strategic purpose was that the prime partner, Sydney Water, had been under severe public criticism because of outbreaks of giardia and cryptospiridium in its water supply only a few years earlier. As a long-term service provider in Sydney, the client was committed to improving its relationship with the community. This made it imperative that the alliance team shared its commitment to excellent outcomes in noncost and schedule performance areas, such as community relations, safety, and environmental management. Sydney Water believed that this could be best ensured if it participated in the project team through an alliance approach.

At the time of commencement, relatively little was known about the ground conditions, and the tunnel had not been designed. Given the tight time frame, the availability of tunnel-boring machines (TBMs) was critical, as these had to be sourced on subcontract from elsewhere in the world. The first stage of the project, of about 18 months, involved a detailed exploration and design phase. Without this, the contractual risks arising from latent conditions would have been unacceptable to any government client. That made completion in an extraordinarily short period of time vital, obviating against a conventional strategic-planning process; instead, a constant process of thinking through the future perfect was implemented. The process comprised imagining a future and then seeking to realize it, subject to constant revision, an approach that seemed inductively to fit Schütz's conception of the future perfect.

The degrees of ambiguity and uncertainty inherent in the project were high because of the deadline, the lack of engineering information, the lack of information about the characteristics of major pieces of technology (the TBMs), and also the characteristics of the communities affected by the project. Because of the more than usual degree of uncertainty, the project was to be managed in a unique way. Instead of a tender process, where the entire project has to be specified in advance and those specifications made public for community comment, Sydney Water invited expressions of interest from companies willing to enter an alliance to deliver the project. The specifications were only 28 pages in length (unheard of in conventional construction, where the bill of works and associated contractual documents can run into many thousands of sheets). As the project would involve concurrent engineering, much of the design was unspecified. Specified in detail were the agreed principles that the partners were to commit to as the means for resolving issues within the alliance. These differed markedly from traditional detailed construction contracts, with the prospect of arbitration when agreement broke down. A typical approach to selecting partners for the alliance was followed (cf. Stiles and Oliver 1998), choosing the partners on the basis of their commitment to the process envisaged.

Having thought of the usual way of doing things, with the usual problems that this might entail, with worst- and best-case parameters, they then set about trying to think of extraordinary ways of creating the desired outcome. The outcome was easily encapsulated colloquially: "a lot less shit and rubbish in the harbour" and sparkling blue water for the TV cameras covering Olympic sailing and swimming events, as well as, in the long term, less pollution generally for residents and tourists. The detailed design of the tunnel was commenced by the alliance once it was established in early 1998 through first defining a business as usual (BAU) case, using conventional scenario planning approaches: the outcome that would be most likely to occur with the project if they designed and constructed it through traditional planning methods, such as reverse scheduling. However, the project partners wanted to do much better than this: They wanted breakthrough innovations. The alliance partners sought to imagine the project in terms of outcomes that were so good that everyone benefited: the marine life in the harbour (who were a potent symbol in the project iconography); the residents around the foreshore and under the tunnel route; the local communities with whom they would interact in the process; the Olympics organizers; public works contractors throughout the State of New South Wales, and the employees, contractors, and client themselves - the members of the alliance. An innovative approach to organizational collaboration framed their thinking and action.

\section{An Innovative Approach to Organizational Collaboration}

Management consultants experienced in large-scale construction projects helped design a project culture. ${ }^{4}$ The consultancy assumed that the alliance would only achieve its objectives if staff at all levels shared the same values, believed that the project was "something special," and had only its ultimate success in mindrather than sectional "home" organization interests. They recommended that cohesiveness could be fostered through creating a project culture that was explicitly designed and crafted to encourage shared behaviours, decision making, and values. A list of value statements was produced by the PALT (Project Alliance Leadership Team), which comprised the formal statement of the culture: The two core values were striving to produce solutions that were "best for project" and having a 
"no-blame" culture:

(1) Build and maintain a champion team, with champion leadership, which is integrated across all disciplines and organizations;

(2) Commit corporately and individually to openness, integrity, trust, cooperation, mutual support and respect, flexibility, honesty, and loyalty to the project;

(3) Honour our commitments to one another;

(4) Commit to a no-blame culture;

(5) Use breakthroughs and the free flow of ideas to achieve exceptional results in all project objectives;

(6) Outstanding results provide outstanding rewards;

(7) Deal with and resolve all issues from within the alliance;

(8) Act in a way that is "best for project;"

(9) Encourage challenging $B A U$ behaviours;

(10) Spread the alliance culture to all stakeholders.

All staff would be expected to think creatively and laterally to come up with solutions considered best for this project rather than merely to implement secondbest solutions already known from previous projects. In this way they sought to instill future perfect thinking in the everyday life of the project. Intricately linked with this "best-for-project" mentality was the "no-blame" element: Staff would be expected to find solutions to problems rather than to dispense blame. Additionally, every alliance partner committed to making the most appropriate, technically skilled, and team-oriented staff available for the project, even if that meant withdrawing them from other projects. Induction workshops were held to ensure that everyone, including subcontractors, understood

\footnotetext{
that the alliancing concept means what is best for the projectmeaning there might be things I like from my experience but it may not be good for the project.... We have five objectives in the project: time, cost, ecology, safety, and community. We always think of those things, we always challenge ourselves with those things, we are guided by them (Project Leader, 2/01/1999)
}

The project sought to exceed $B A U$ expectations and achieve outstanding results. In order to do this, they were constantly thinking in the future perfect: What would they have to have done to achieve the outstanding performance across the demanding range of indicators to which they had committed? When contrasted with the more traditional construction methods of adversarial exploitation of contractual details for profitable advantage-which are not at all oriented to the future perfect, rather more the future imperfect-and the prospect of their ultimate resolution in arbitration (Clegg $1975,1992)$, then the uniqueness of the project approach can be grasped.
The basis for the contractors and client benefit was a risk/reward calculation. The project agreement provided for a risk/reward regime based on performance compared to project objectives defined in terms of five key performance indicators (KPIs): cost and scheduleno surprises there-but also safety, community, and environment-which are not usually part of construction KPIs. There was one nonnegotiable performance criterion, the completion of the project for use by the Olympic games. While the alliance had the responsibility of defining $B A U$ objectives in terms of suitable criteria, there was no precedent for a construction project being assessed against such parameters. To ensure independence, external consultants were engaged to review the benchmarks for the noncost/schedule criteria that had been developed by the alliance. For each area, performance levels ranging from poor to outstanding were defined-with the brief being simply to define outstanding through the future perfect-what would an absolutely spotless report card and review of the project require? The specialist consultants also assessed and reported performance against all criteria regularly throughout the project. Success against the noncost/schedule criteria was critical for project success both in commercial and overall terms and, as such, this area presented the alliance team with significant risks.

There were positive and negative financial outcomes for performance on each of the objectives in the risk/reward process. Financial rewards were payable on a sliding scale for performance above $B A U$ to outstanding. All objectives except cost had a maximum amount. Financial penalties accrued when performance was below $B A U$ and, most importantly, performance in any one area could not be traded-off against any other area that was represented by the KPIs. Only outstanding performance against all five KPIs would yield the maximum return; less than this in any one area would diminish that return and adverse performance would put the reward at risk as penalty clauses began to bite. To make the future perfect concrete meant constructing something that could be imagined as already complete and subject to audit. Thus, in each area performance processes and outcomes were constructed on which the project would be assessed.

\section{Methods}

Within the case we conducted in-depth qualitative research: We attended every monthly, and later bimonthly, project alliance leadership team meeting, as well as occasional informal meetings; collated newspaper clippings related to the project; and collected public relations materials issued by the leadership team. In the ethnographic tradition, these archival and published 
records were also collected and analysed, as were local, state, and national media articles. We also examined reports from the independent assessors. Thus, over an 18-month period, research team members attended all leadership meetings of the PALT. The meetings monitored performance, discussed project-level learning, sought to solve problems, and determined future strategy. As audiocassette taping of meetings was not allowed, a laptop computer was used to record key points. The meeting secretary read these notes, which we supplemented by the minutes, to ensure nothing was taken out of context. ${ }^{6}$

\section{Data Analysis}

The attendance at all PALT meetings inspired the line of enquiry followed in this study. It became evident that temporal issues were of critical importance to the PALT members. The temporal nature of the data was also an issue consistently highlighted by three independent coders employed to assist in data analysis. It became obvious to us that the uniqueness of the project had created a unique concentration on the temporal aspects in the strategic management of the project. The transcribed interviews and the ethnographic notes were initially analysed using open-coding techniques (Strauss and Corbin 1990). Principal researchers and research assistants participated in a joint open-coding workshop and specific training sessions in which we employed examples for coding and checking of codes. The qualitative software package QSR NUD*IST Vivo (NVivo) assisted in our coding. We noticed that managers sometimes projected events, actions, and behaviour that had not yet occurred into the future as if they had already occurred and were lying in the past. They would then retrospectively plan the actions that would lead to accomplishing that outcome.

The pattern emerging was intriguing and we started to look for other instances. In line with the work of Schütz (1967) and others (Rollier and Turner 1994, Weick 1969), we coded such instances as managing by futureperfect strategy. We then checked all codes against the final categories, used NVivo to search all documents for the final categories, and collated them in a comprehensive coding data report spanning all interviews and PALT notes. We sorted the report by time of interview or meeting in order to see how management strategies and processes changed over time. Table 1 provides excerpts of some of the data coded as future perfect strategy. Each independent coder created such tables, and each coder was required to justify their reason for coding text as they did. To get to future perfect strategy, coding went through three iterations of coding. We did not want to break down text into further codes for fear of moving data too far away from their original meaning (Bansal and Roth 2000). First-order coding was grouped under the issue of "time" and paragraphs of text were coded as time if they contained words pertaining to time, created from a thesaurus program called WordWeb $\odot$. Text coded included words like temporal, time, schedule, moment, minute, hour, second, instant, occasion, season, instance, clock, period, era, forever, sometimes, continuous, end, start, beginning, stop, now, later, early, tardy, and other words and variations of words (for example late, later, lately). In the second stage of coding using NVivo, chunks of text were analysed for the conceptual relevance to the notion of future perfect. Text that appeared to be discussing issues as either completed or thrown forward were then isolated. The final stage of coding then isolated all text that had some kind of strategic intent. Therefore, text like "In two weeks from now I'll be lying on a beach laughing about all this community crap" (Project Manager, PALT, 8/28/00), while anecdotally amusing, was judged not to be strategic, whereas the text contained in Table 1 was judged by all three independent coders to be strategic in its intent. By strategic we mean the text related to issues important or integral to the project.

\section{Discussion}

Through the future perfect strategy the partners were committed to completing the infrastructure by July 31 , 2000. Consequently, project leaders recognized that they had to challenge the normal $B A U$ mentality and behaviour in the construction industry if they wanted to achieve the optimal outcome. Business as usual normally meant fixing things as one went along: This was a special project needing special behaviour grounded in a specific value - the uniqueness of the project and the excitement that this created for those working on it. The project leaders tried to bring all staff and community members on board by making them excited about the project-"We need to get them hooked on the excitement of the project" (PALT meeting, May 1999). The excitement that the project leaders felt was in the sheer creativeness of the project, the constant envisioning and revisioning in a future perfect mode, the audacity of their setting themselves much more complex KPIs than was normal, and the returns that excellence would deliver. By focusing on the uniqueness of the process, staff, and community could work together to solve any problems. Rather than focusing on inevitable construction problems as sources of profitable variation for their firm, members of the project would work in ways that would 


\section{Table 1 Examples of Text Coded as Future Perfect Strategy}

Text
...Everything we do is difficult because our contract is so
bloody different and no one is used to it-for the whole
team, it's a very new environment for them. We needed to
do more research but we can't, we have no bloody time...so
we need to make what we do a way of life, need to make it
clear that the bonus can go up and down, make it clear to
them what they get when we finish will be bigger than
anything they would otherwise get. As long as our outcomes
are better than BAU on all our performance indicators...
We made a number of changes to the tunnel designs, made
Scotts Creek tunnel larger because of geotechnical and
machinery issues that we couldn't have known in advance.
These changes acted as a catalyst to Scotts Creek
community's revolt because these changes were never in the
plan. But [expletive] they [community] can't keep referring
to the plan because just about everything's changed since we
made that plan public ...

made that plan public...

[In response to community criticism] ... (PD) What are the options? Let's think what's best for project? Now, if the board make a contractual change it has to advise the alliance of this. But the board does not seem keen on spending money to solve a problem that is not objectively there. But we all know the problem will still be there anyway, and, when it is, we won't have the budget to deal with it. So how do we deal with it now to avoid it later?

$(\mathrm{PL})$ We need to pre-emptively prepare to meet with other CLCs (Community Liaison Committees) and have people prepared to soak up the abuse and put out fires.

(PD) Well I can tell you one thing, if this had been a non-Alliance relationship the decisions would have been made 10 weeks ago to smash through.

[Conversation on the below BAU safety performance] (PD) Culturally, were just not getting there on safety. We can't expect or accept the old "death a mile" attitude.

$(\mathrm{PL})$ You can put in a great safety process, and we have had independent auditors say this is the best project he has ever seen in terms of processes to combat accidents... but if all a team hears is production, production, production what do you expect? Safety and productivity should go together, drive each other!

\author{
Conversation \\ Between Project \\ Director and \\ Project Leader-PALT \\ Meeting (6/16/00)
}

Analysis

Project Leader-PALT

Meeting (3/31/99)

Project Manager-PALT

Meeting (3/13/98)

Conversation

Between Project

Director and

Project Leader-PALT

Meeting (3/13/98)
This passage reflects the inability to plan strategically for changes to design under future perfect conditions, because there is insufficient information at the outset of planning. Future perfect strategy emerges as changes to the plan as information becomes available: The emergence affects stakeholders, such as the community, whose rational expectations are that there is a plan and that the Project is "rorting" it.

In this passage the respondent recognizes that, in reality, in the world of the technically rational engineer, the problem that the community in question is agitating about is not "really" a problem. But he also knows that it will not go away. So, even though it is not a real problem, it still has to be dealt with as if it were, in the here-and-now, in order to avoid the problem undermining the future perfect achievements of the project. The CLCs will have to absorb present anxieties to secure future perfect outcomes, rather than the project crashing through with what it knows is the "right" technical solution, irrespective of community sentiment.

In a normal contract a "death a mile" in a hazardous operation, such as tunnelling, is the usual expectation. The contract is falling behind on delivery. It is important for the future perfect strategy that the culture should not allow anyone to think that safety can be sacrificed for completion. The future perfect has to harness both together, and so management steps are spelt out as 
Table 1 (cont'd.)

Text
(PD) We need to move fast and have a week-by-week
improvement. From now on site supervisors are going to
have daily reports on safety scores. I mean it. I want them to
have daily reports and they will come back in a month, two
months and show me how much they have improved. I want
everyone on this, unions, supervisors, contractors, everyone.

[On safety and schedule] You know, I think we need to ask ourselves what happens when you have two opposing incentive schemes acting as reinforcers. One for safety, the other for schedule! There is a need to link working faster to working safer, and I don't think this was addressed. So [project leader] could you please get someone working on that issue?

The project team must be perceived to be in front of the game, leading it. Not behind the game. So PALT must assist the project teams to achieve results. We know where we want to be, where we want to go, where we want to finish up. We need to plan the end and work out each step to get there so everything is synchronized. We need ownership over the deliverables at the end of the project. The ultimate product is the built product!

[Discussion on the possibility of not meeting schedule] (PD) Well, we have a practical completion date of October 12 and we are going to meet that practical completion date a month early. So I think we have a good case to show we are doing everything in our power to meet the completion date.

$(\mathrm{PL})$ : The Olympics will also have an effect upon what we can and can't do. But we were really stuffed around by the government and some people in the community. So what if we claim... [cut off].

(PD): I am uncomfortable in revisiting past decisions that we made and try and change them. So we should look at only current issues and events, and future issues and events and work on that basis only.

If someone like Sydney Water said, "change what you're doing," we would do that. But in the meantime, one of the requirements that we entered into, or one of the objectives we entered into, is that we would talk and liase about these things with the community. We would consult and communicate as we go, but see, that objective is now threatening us in meeting our other objectives: costs, schedule, environment, and safety, and particularly cost and schedule. So I said to them (the community), we are going ahead, as we've said, and your recourse now is, legal, political, err, you know, you can lobby, try and get things changed through the legal or political processes. You always have those rights; we cannot take those rights away from you, even if we wanted. We think you're going to exercise those rights, so we will not give you the same level of information about what we're doing as we previously have.
Project Director-PALT Meeting (1/18/00)

\author{
Project Leader-PALT \\ Meeting $(1 / 18 / 00)$
}

\author{
Conversation \\ Between Project \\ Director and \\ Project Leader-PALT \\ Meeting (8/15/00)
}

to how safety will be managed to achieve this. Both safety and completion are being conceptualized in relation to the future perfect rather than to normalized expectations or existing progress completion on the present project.

In a future perfect world all the KPIs reinforce each other-that they should do so becomes a matter for project culture design.

Starting from the end state, the imagined future perfect, the project needs to work out what it has to do to get there.
The realization of the future perfect is prescribed, literally, as a date. Then the relation between current issues and events and the achievement of this future perfect is fixed by reference to the future perfect rather than its revision because of the exigencies of the here and now.

Interview with
Project Director
About Community
Opposition to
Tunnel Venting
$(8 / 02 / 00)$

Interview with About Community

\author{
The future perfect limits are made \\ evident in their breaching by the \\ community. While the PALT would \\ change the parameters of the design \\ that they have envisaged in \\ response to authoritative input \\ from, for example, Sydney Water, \\ they will not do it for input from the \\ community. The limits of \\ community power and \\ responsibility are made evident \\ when the community breaches the \\ role that the PALT would prefer \\ them to play in the future perfect \\ scenario.
}


deliver whatever was best for project. This extended to involving the union representatives as vital to the success of the project: They were just as committed to the alliance as management, having shared in the culture workshops that created a common sense of "governmentality" for the project (Clegg et al. 2002).

\section{The Future Perfect Strategy}

When we encountered what we were to term the "future perfect strategy" in action we found something the existing literature had missed, a proposition we tested by scanning the strategy literature. Mintzberg (1990) presents the relevant schools of thought: In Table 2 we demonstrate how they might have been applied to the case, and the lack of explanatory power that these existing strategy approaches had in accounting for what occurred within the case.

The discipline of collective imagination of a future perfect, framed by the designer culture and bound by the governmental strategies of the KPIs and the risk/reward scheme, tied the loose coupling of the collaboration together, as regularly reported in the monthly PALT meetings. In addition, specific future perfect strategies were routinely used as management devices throughout the project. We were able to identify three specific means of managing through the future perfect strategy. These means included the creative use of strange conversations; the rehearsal of end games and the prac-

Table 2 Mintzberg's Descriptive Schools of Thought

\begin{tabular}{|c|c|c|c|}
\hline School & Key Features & Relationship to the Case & Theoretical Added Value from Present Study \\
\hline Entrepreneurial & $\begin{array}{l}\text { Strategy as vision and } \\
\text { mission. Key role for } \\
\text { is to instill } \\
\text { a shared sense of } \\
\text { vision and objectives. }\end{array}$ & $\begin{array}{l}\text { Established through the } \\
\text { PALT A multiple/ } \\
\text { collaborative leadership } \\
\text { leadership team unified } \\
\text { around the "best for project" } \\
\text { culture (see culture). }\end{array}$ & $\begin{array}{l}\text { Leadership is neither individual nor hierarchical, } \\
\text { but collaborative and collective. Entrepreneurial } \\
\text { strategy lacks detailed explanation of how to } \\
\text { ensure shared vision and objectives in } \\
\text { interorganizational collaboration as it presumes } \\
\text { unitary managerial prerogative. }\end{array}$ \\
\hline Learning & $\begin{array}{l}\text { Strategy as incremental, } \\
\text { developing over time. } \\
\text { Organization learns from } \\
\text { its environment and } \\
\text { adapts strategy accordingly. }\end{array}$ & $\begin{array}{l}\text { Strategy develops through } \\
\text { learning from doing with what } \\
\text { was available, in conditions of } \\
\text { very high uncertainty. }\end{array}$ & $\begin{array}{l}\text { In the case of the PALT project, learning was not } \\
\text { incremental but a highly accelerated and focused } \\
\text { process. Strategising, therefore, was always linked } \\
\text { to the projected future (future perfect) and not } \\
\text { linked to rational planning. }\end{array}$ \\
\hline Political & $\begin{array}{l}\text { Strategy as negotiation } \\
\text { and compromise. } \\
\text { Multiple stakeholders } \\
\text { with multiple views. }\end{array}$ & $\begin{array}{l}\text { Multiple stakeholders and } \\
\text { interests aligned through } \\
\text { PALT's commitment to } \\
\text { designer culture and } \\
\text { risk/reward system. Multiple } \\
\text { stakeholders were aligned } \\
\text { through an intricate system of } \\
\text { KPIs, such as community, } \\
\text { ecology, safety, budget, } \\
\text { schedule. }\end{array}$ & $\begin{array}{l}\text { The political school of strategy generally works } \\
\text { with an implicit model of zero-sum power: In } \\
\text { order for one party to gain power, the other party } \\
\text { or parties have to lose power. This is a negative } \\
\text { rather than positive conception of power. The } \\
\text { PALT worked with a positive conception of } \\
\text { power. They explicitly framed the members of the } \\
\text { various organizations forming the project in a } \\
\text { "Designer Culture." To bind members further, a } \\
\text { "Risk/Reward" scheme was implemented } \\
\text { whereby, through explicit evaluation of the } \\
\text { project's performance on the five KPIs, a positive } \\
\text { culture of power was created. }\end{array}$ \\
\hline Cultural & $\begin{array}{l}\text { Strategy as shared } \\
\text { values and the } \\
\text { adherence to the } \\
\text { "way we do things } \\
\text { around here." }\end{array}$ & $\begin{array}{l}\text { The creation and use of a } \\
\text { Designer Culture (see Clegg } \\
\text { et al. 2002) that made it } \\
\text { possible to instill the "what's } \\
\text { best for project" culture. } \\
\text { Dispersed across and down } \\
\text { the four organizations and to } \\
\text { subcontractors through an } \\
\text { intricate system of banners, } \\
\text { induction workshops, regular } \\
\text { informal and formal meetings, } \\
\text { incentives, etc. }\end{array}$ & $\begin{array}{l}\text { Instilling the "what's best for project" culture was } \\
\text { complex and done at the early stages of the } \\
\text { project, but required careful management } \\
\text { throughout the life cycle of the project, as well as } \\
\text { an explicit material reinforcement through the } \\
\text { relation of risk/reward and KPIs. }\end{array}$ \\
\hline
\end{tabular}


Table 2 (cont'd.)

\begin{tabular}{|c|c|c|c|}
\hline School & Key Features & Relationship to the Case & Theoretical Added Value From Present Study \\
\hline Configurational & $\begin{array}{l}\text { Strategy is crafted, } \\
\text { as opposed to planned, } \\
\text { and focused on } \\
\text { engagement developed } \\
\text { through experience } \\
\text { and commitment. }\end{array}$ & $\begin{array}{l}\text { The configurational school, } \\
\text { while it is broadly in line with } \\
\text { the approach developed here, } \\
\text { does little to provide a theoretic } \\
\text { tool for making sense of this } \\
\text { project. It assumes that the } \\
\text { organization is unitary and that } \\
\text { strategy is an emergent } \\
\text { intraorganizational process. } \\
\text { Hence it is a perspective difficult } \\
\text { to apply to the role of the client } \\
\text { and interorganizational } \\
\text { collaboration in project } \\
\text { management. Knowing the } \\
\text { complexity of strategy and } \\
\text { treating it as an emergent } \\
\text { process does not remove } \\
\text { tension between strategic intent } \\
\text { and client expectations, which } \\
\text { are inextricably linked in } \\
\text { project management. }\end{array}$ & $\begin{array}{l}\text { The configurational school assumes that strategy } \\
\text { unfolds at irregular intervals and at different } \\
\text { stages, whereas in a complex project management } \\
\text { system it is a continuous flow process that it is } \\
\text { constantly under revision in many loosely } \\
\text { coupled situations. And, in the Olympic project, } \\
\text { these situations were neither loosely coupled to } \\
\text { any formal blueprint nor any set of detailed plans. }\end{array}$ \\
\hline
\end{tabular}

Note. Adapted from Mintzberg, H. 1994. Strategy formulation: School of thought. J. W. Fredrickson, ed. Perspectives on Strategic Management. Harper-Collins, New York.

tice of workshopping, and the projecting of feelings, concerns, and issues. Each of these adds to our knowledge of how the future perfect strategy is possible, and so we elaborate on them here.

Strange Conversations. It was Karl Weick (1979, p. 200) who introduced the notion of strange conversations to the management literature, a topic that he took from ethnomethodology. Garfinkel (1967), the founder of ethnomethodology, would often proceed, methodologically, by making conversations strange. For instance, he would instruct his researchers and students to continually interrogate people whom they encountered in quite normal everyday settings, such as the family or shopping. His general injunction was to ask, "What do you mean by saying...?" He instructed them to do this to elicit the everyday grounds of routine actions. Garfinkel's point was that deep layers of tacit knowledge supported even the most mundane utterance. Using this form of questioning was one way of breeching the rules of normalcy to try and reveal the nature of these tacit assumptions. At the point at which people became angry at the conversational turn, then these everyday rules for making sense were breached. Normally, these rules would not be visible-ruptures made the tacit explicit. However, as one of his experiments, written up at length in McHugh
(1967), showed, strange conversations could be generated through apparently normal conversational routines. In these experiments he used random assignment of answers to the questions that were asked (the answers were either "yes" or "no") by subjects seeking advice and unaware of the experimental situation that they were involved in. These responses generated conversational sequences in which the actors desperately sought to minimize the strangeness of the conversations they increasingly entered into, by showing that they (such subjects) were capable of making sense of even seemingly bizarre and contradictory interaction sequences.

We did not have to manipulate our subjects to produce strange conversations, but took our cue from Weick (1979). Weick defined strange conversations as ones where the agenda, process, and outcomes were unclear. A great many community meetings were associated with the project: In each of these, the agenda was unclear, the process highly emergent, and the outcomes unknown. In these meetings community members were invited to express anxieties and make suggestions in relation to the project (almost all of which took place beneath the surface, of which they had little knowledge). What they proposed was often a surprise that, in terms of the rationality of the engineers involved in the project, made little sense: For instance, they were concerned about 
the visual obtrusiveness of the aboveground works, the noise, mud on the roads, and potential loss of access to walk their dogs or for children to play. These were all secondary considerations for the engineers, intent on building the project.

The conversations initially were strange because the premises from which each of the two sides came were so different: Initially, some tensions occurred in some meetings. However, these strange conversations helped to produce creative solutions to many local community relevancies, such as the diagnosis of the aesthetics of the works. One site was diagnosed as "ugly" in conversations between the project and the community. That the community liaison officers would be addressing aesthetics was not an outcome that had been envisaged prior to these conversations. Often, in the initial meetings, it was unclear what it was that was being discussed, as talk ranged so widely, in terms of the community member's emotional and aesthetic response to the engineering works. In fact, it was often the case that the eventual outcome informed what it was that the conversations had been about: For instance, once the proposal for the concealment and beautification of one of the sites had emerged, then it crystallized as what had been wanted all along, even though at the outset this was not clear at all. Later in the project, community liaison officers found themselves organizing BBQs between community and project members, where more such intriguing conversations occurred.

End Games and the Practice of Workshopping. End games helped concentrate minds on the future perfect strategy in the project. End games occurred frequently, as project completion was enacted in the future perfect. Here is an example that occurred at the January 2000 meeting, when a project leader reminded everybody of the objectives. He said:

We know where we want to be, where we want to go, and where we want to finish up. We need to plan the end and work out each step to get there so everything is synchronized. We need ownership over the deliverables at the end of the project.

The ultimate project is the built product.

As we made clear earlier in the paper, it was the absence of the usual project prescoping and its incorporation in a complex bill of works that made the project unique. It was designed as the process unfolded-an unfolding that did not always develop according to expectations. For instance, in March 1999, one project leader exclaimed, "It comes down to we have lost 10 weeks but we have only been on the job for 26 weeks!" This particular project leader then complained that suggestions being made on how to deal with the slippage were reactive. The project leaders needed to be more proactive in orientation. He seemed to suggest updating their future perfect planned strategies. Implicitly, he said that they should still project the infrastructure as something that would be built by July 31, 2000. At the same time, he suggested that they should plan backwards for the 78 weeks that were left for this particular phase and take into account that they had only accomplished the amount of work budgeted for 16 weeks in the previous 26 weeks. So, while the original planning had been based on 104 weeks, they would now have to plan as if they had never had more than 94 weeks (of which only 78 were now left). ${ }^{7}$

At the August 1999 PALT meeting, where slippage on the completion date was at issue, one of the project leaders used the end game technique to challenge his colleagues to think in future perfect terms:

\footnotetext{
Look, I'd like not to have a stretched target. Where will we really be in two or four weeks? Think hard about what you want to be judged on. What are those numbers you want to be associated with? You know that this will come back to you. We will ask you, have these forecasts been met? What will you say?
}

The answer, which was simply "We can meet it," was clearly not what he had hoped for:

\begin{abstract}
Don't set a stretched target and miss it. If you cannot meet it, change it now. I mean we are going to have a very serious discussion with government. We will say to them, we need to increase time, increase costs, because you stuffed us up. They will say ok, but cross-examine us first.
\end{abstract}

He wanted them to project themselves into a future where-as the end game-government agencies would question them and then think backwards towards the present. How would they cope? How would they feel? He knew that the project would be judged by the outcome and wanted them to think backwards from the outcome. A representative of an indirectly linked organization, who only attended that one particular PALT meeting, stated this bluntly:

\footnotetext{
Well, I can guarantee you PALT members one thing! The Minister will ask what day you will finish, if you are not finishing on the day you said you were going to finish. You will have etched this into stone, on a report and you will be judged on this date!
}

He was told that there were contingency plans and that working with machinery was, at best, like a lottery. Another project leader also insisted on future perfect thinking at this meeting by asking, "If we were meeting the Minister tomorrow, what would we say the finishing date would be?" The project leaders responded by 
agreeing "OK, by such and such a date we will have had a risk analysis on schedule done."

The significance of end games was that they worked as aids for visualization of the future perfect and enabled the PALT to focus on the future perfect they were seeking to construct. One of the key techniques used to maintain future perfect focus on the end game was workshopping. When it looked as if the project might run over schedule, the PALT agreed to have a workshop to address the alignment of the five key objectives between headquarters and construction sites (PALT meeting, June 1999). They agreed that by the time of the workshop, one of the project leaders would have met with the program managers responsible for the key objectives. He would have discussed the alignment of the overall objectives with those of the particular construction sites. Additionally, he would have codified the learning breakthroughs at each construction site, so that they could identify how they had reached their outstanding achievements. Further, he would have discussed the workshop agenda with management consultants and would have arranged a workshop venue. Once again, the PALT engaged in future perfect strategy.

Projecting Feelings, Concerns, and Issues. Although the members of the PALT team were almost all engineers, people with a technical background who were more professionally versed in technical than social construction, there was some explicit recognition of the importance of social construction in one aspect of the PALT meetings. The agenda for each meeting originally contained a section titled "Projecting Feelings, Concerns, and Issues." We were rather surprised when we first saw this in action: We had not expected such empathetic and social maintenance work from highly professional engineers. Any member could raise anything under this recurring agenda item, with the issue remaining on the agenda until "it was no longer important or was addressed to the satisfaction of the person who raised the issue in the first place." The inclusion of this clause was supposed to ensure that future perfect thinking maintained a reality check: If an issue had been constructed in regard to any aspect of the project that was causing concern, then it was reiterated monthly, until it was no longer a matter for concern. While some of these feelings, concerns, and issues were quite technicalabout scheduling and the like, others concerned more complex community relations. ${ }^{8}$

The technique was significant-it ensured that the future perfect agenda was open and democratic in its projections among those in the top leadership team. It created a space in which emotional aspects of the project could be discussed (Fineman 2000, Albrow 1997). Increasingly, the routinized use of the item-which after a while became merely a matter for noting rather than action and was then later abandoned-signalled the limits of future perfect thinking when confronted by community matters that were outside of project control. It was this that alerted us to the limits of future perfect strategy, a point we will go on to develop in the next section.

\section{Anticipated and Unanticipated Implications}

In this section we wish to focus both on some outstanding achievements identified in the use of future perfect strategy, as well as some unanticipated drawbacks. We expected the project to be completed on time, given the people, the PALT organization, and the careful design of the management approach. Early on in the project, as we saw some of the key KPIs slipping, there was an expectation the incredibly high goals set may not be achievable and that business as usual would prevail: If this were the case, then the project would end up in an acrimonious wrangle, a normative as well as statistically normal outcome in the industry. In addition, making the project more complex and hazardous, there were issues beyond the control of the project leaders. These included a State election that stirred political resentment in one of the affected communities; the unanticipated collapse of some subterranean rock; the need for more complex tunnel bolting than had been projected; damage to houses due to subterranean movement in another area, as well as a panic orchestrated about the potential polluting effects of the tunnel venting system. Also, there existed a tight labour market in the pre-Olympic boom conditions prevailing in the NSW construction industry. Finally, after permission had first been granted, there was a refusal to dispose of materials as agreed. Although these factors contributed to the project running late and slightly above cost, it was, nonetheless, a highly innovative and successful project, as we shall see.

\section{Project Innovations}

Much of the innovation achieved was technical. Because of the time required to source the TBMs, order them, transport them to site, and commission them ready for use, the decisions on equipment were made very early, at a stage when relatively little was known about the ground conditions. This was a major risk and created numerous challenges. First of all, once the geotechnical investigations had been completed, an optimization exercise led to the redesign of the tunnel configuration 
to ensure safer working conditions in two critical areas where unexpectedly poor conditions would have slowed the project and made the excavation more hazardous. The resulting design accelerated construction, saving some five weeks in the program. Other tunnel design innovations included raising the tunnel in one area to position it in a more suitable rock formation, extending it in another location to improve the environmental outcomes by extending the catchment area of the overall overflow facility, and an improved understanding of the rock condition enabled the team to reduce the extent of concrete invert lining required. Finally, the tunnel configuration was altered because of the timing of equipment arrival, and a larger-diameter tunnel was constructed where a smaller one had been envisaged.

A number of design innovations to the operating equipment of the completed facility led to alterations in the design of a treatment plant, two pumping stations, and an electrical switch room. This led to savings in buildings and considerable saving in excavation for underground plant rooms. Reductions in excavation had time, cost, and safety implications. Related to this area also, modifications in the design of vents led to significant reduction in excavation and enhanced safety. In a traditional contract, design changes of this magnitude could not have been contemplated without substantial cost renegotiation and probably delay. Also, there would have been no motivation for the generation of savings throughout the contract period, and it was this aspect of the use of the future perfect-linking it to the outcomes - that, more than anything else, produced the innovation.

There were also a number of significant constructionprocess innovations. An automated laser profiling system (ALPS) was developed to improve the control of excavation with a road header. This led to reduction in overexcavation and, hence, had efficiency and safety implications. It also reduced the requirement to check the alignment of the excavated surface by survey. The TBMs had to be modified throughout the project in response to changes in ground conditions, all of which were unknown when the project was commenced. There were a number of significant innovations in materials handling, both underground and in the disposal of spoil to an inland reclamation site. Large lengths of continuous conveyor, with the use of booster stations, reduced the need for underground haulage in a number of locations; a shuttle conveyor system was designed for the efficient loading of barges; and the use of long-reach excavators for unloading of barges avoided the requirement for wharf strengthening. Also, the TBMs were assembled elsewhere, shipped to Sydney, and unloaded on a pontoon barge, avoiding the costly strengthening of wharf structures to carry the load of the TBMs. All of these were excellent examples of future perfect thinking in operation: The innovations were achieved through thinking in the future perfect as to how to hasten time, rather than just doing business as usual.

A number of innovations were motivated by environmental considerations. These included the use of closed water systems and a runoff collection system at one site to ensure that contaminated water did not leave construction sites. In another area, the realignment of a tunnel reduced the risk of disturbing contaminated material in a cut-and-cover operation. The construction of a major portal structure for the loading of spoil onto barges reduced visual pollution in a sensitive area and significantly reduced noise emissions. Also, an innovative technique effectively eliminated construction noise during the driving of piles in this area.

In terms of overall performance, the use of noncost/ schedule performance measures was innovative in itself. This appears to have been a unique aspect of this project. It placed the alliance team under pressure to perform at a high level across a wider range of performance characteristics than is normally the case on such projects. This forced the management team to maintain its focus across all the areas of performance defined at the outset as being critical by the client in terms of their everyday accomplishment. None could be glossed over in the interests of expediency favouring construction rate or cost, though these are common compromises made on construction projects. It should also be recognized that this was a project working under extreme time pressure and considerable pressure from the community.

\section{Unanticipated Consequences}

Tasks "involving judgement, ambiguity, creativity, and volatility of environment" (Keen and Scott-Morton 1978, p. 68) are especially hard to program. Future perfect thinking has been seen as useful for unstructured, nonprogrammed tasks because the methodologies needed to solve such problems are rarely determinable in advance (Rollier and Turner 1994). The construction project involved high ambiguity, needed creative solutions, and occurred in a highly volatile environment. Sometimes the solutions developed within a cultural commitment to the future perfect became a part of the problem. For instance, the best-for-project and no-blame culture had been intended to reduce ambiguity, yet sometimes seemed to amplify it. According to a project leader, some members mistook the no-blame aspect of the culture to mean:

That you couldn't call anybody up on what they hadn't done.

That it meant no one could go up to someone and say "tighten 
your schedule, you said you would be here at two o'clock. I've structured my day around you being here at $2 \mathrm{pm}$ and you arrived at $3 \mathrm{pm}$. I'm losing confidence that you are going to do what you say you're going to do!"...I think that [noblame culture] is something Australians find really difficult to deal with. In Australia it's more like "Hey, you get lost or something?"... That happens all the time and is a real problem where there are many parties involved (2/18/2000).

In Australia there is a phrase that people often use, "She'll be right mate," meaning do not worry, do not get angry; there may be a problem, but it will be good enough when the project's finished. The "she'll be right" culture did not map easily on to a project that relied so much on future perfect thinking and proclaimed itself a "no-blame culture" to encourage innovation. It tended to make the need for accountability seem like a way of attributing blame; conversely, for some members, the no-blame culture was seen as just a local version of the "she'll be right" philosophy.

The best-for-project principle also contributed to problems. Despite its aims, the project had not always employed the best and some of the best left the project to work for other projects or companies. Hence the project leaders were forced to make changes to staffing:

It was obvious to us that individuals have a lot to do with the achievement of a project. So, you can never get past the issue of people being everything, because they are. But in this project we did not really pick the best people ... but I've got no doubts, with the team that we've got there now, if we had that team from the start, we'd be romping it in. I have no doubts about that! (Project Leader, 2/18/1999).

In January 2000, problems with the retention of staff were voiced for the first time in a PALT meeting. The best-for-project culture could not keep the best people in a highly mobile labour market. While the culture increased certainty about accomplishing the project on time and budget, it also allowed managers to stick to the ethos of strong project commitment as the most appropriate courses of action when it was unlikely that more of the same behaviour would reverse the situation.

Leader 1: ... So [the project leaders] must assist the project teams to achieve results, show them [the staff] we are committed to the project and its future success.

Leader 2: ...We need commitment to the deliverables at the end of the project. The ultimate product is the built product! Leader 3: We have [team-building consultants] between the PALT and [team-building consultants], have we got all the tools we need to get them [staff] all committed?

Leader 1: Well, we can identify all the tools we need.

This exchange during a meeting of the PALT shows the assumption amongst the leaders that commitment to the project and its culture from all staff at all sites would solve problems. Having cast the die for the PALT culture and the alliance method as the way to complete the project on time, on budget, and in excess of expectations, the tendency was to attribute setbacks to factors that were not a part of the future perfect projectionhow could they be, when this was the solution to problems encountered?

Nowhere was the sense of present difficulties more evident than in managing the social rather than the technical construction of the project, particularly community affairs. At the outset, the project team's community liaison process was caught on the back foot. They were not ready for the level of community concern and hostility that they experienced, and the project team had underestimated the resources that were required to manage this aspect of the project. The project operated at five sites, in most of which its relationship with the community was good; however, at one particular site it had a very poor relationship with the local community. One lesson learned was that it is much more difficult to regain the trust of the community once it has been lost than to capture it and maintain it from the outset, as had been done at other sites which had highly successful outcomes. Project teams cannot afford to underresource this increasingly critical area, as it is very difficult to recover from a bad start.

The fact that the alliance's performance in community management had an impact on its bottom line empowered the community and perhaps even made community opposition more vocal. However, there was no formal mechanism for community response: In a sense, the community had power without responsibility, and this skewed the dialogue in the community's favour. The view of senior management in the alliance was that the community problems would have driven a contractor in a conventional contractual arrangement away from the site and led to major cost claims. The structure of the alliance, with its long-term commitment to good community relations on behalf of the client partner, ensured that the alliance had the will, tenacity, and hence the flexibility, to deal with this issue, even at its most confrontational site.

Lukes (1974) has argued that to exercise power is to be responsible for consequences. The project gave the affected communities a voice in the design of the project, empowering potential critics with voice, but it did not create responsibility. The PALT imagined that people in the affected localities would exercise their voice in design and engineering choices. However, some representatives were most concerned about the choices already implicit in the projected design. They would 
have preferred a completely different piece of infrastructure, but were given no space in which to voice their opposition to the framework of choices. People could oppose and propose, as they did when one neighbourhood community council came up with a proposal for the enclosure of one construction site in an aesthetically designed shed. However, this was a minor, if costly, change to concede compared with the profound opposition that other communities had to aspects of the project.

In general, residents and local authorities were not involved in the initial deliberations on what kind of infrastructure to build nor charged with any role in the subsequent management of the project. Although empowered to give voice to their frustration, the community was not included in PALT's circuit of management power (Clegg 1989). For instance, the tight deadline had prevented any community involvement in the initial environmental impact statement. Instead, community concerns were to be incorporated into the concurrent engineering and design: There had been no design parameters "other than the required outcomes described in the Environmental Impact Statement" (Conference Presentation, September 1999). However, the community did not understand the underlying concept and had expected a perfectly specified plan, and in its absence, their puzzlement became an issue to be managed. As one community liaison officer told us,

I am not sure about how much they [project leaders] thought about the whole strategy in the early days. That should have been sorted out ... it was widely misinterpreted by the community (7/27/1999).

The "misinterpretation" was such that some communities were satisfied with neither the means nor the ends. Still, the project leaders continued to expect the community to trust them to create an outcome that represented a technical solution to the problem that the project engineers perceived as important: Creating a tunnel that would keep storm water and sewage out of Sydney Harbour. However, this was not the concern of the one community that generated most of the community issues: They focused much more on the venting of the storage tunnel as a source of possible pollution. From an engineering point of view the project managers saw no problem-but the community were not engineers and engineering solutions could not convince them. Besides, Sydney Water, the organization that had brought them giardia and cryptospiridium in their water supply, hardly seemed able to be trusted when it came to matters of pollution control. If community representatives had been involved with the project in a supervisory board, these issues might well have been aired explicitly as socialrather than technical-issues at an earlier stage.

\section{Conclusion}

Both social and material reality changed in the Olympic project. Materially, a major amenity and piece of infrastructure was developed, while socially a shared culture was built to deliver it, around what we came to characterise as a future perfect approach. We developed this interpretation of the management of the project through intensive case study and fieldwork. We then shared our interpretation at one of the last PALT meetings, where we presented an earlier version of this paper to the members. Indeed, we modified our interpretation as a result of the discussion that this presentation provoked.

Most research (e.g., Rollier and Turner 1994) stresses the quantity and quality of a priori strategies in securing exceptional outcomes. In this project, there were no detailed a priori strategies, other than those constantly reconstructed through the future perfect. Hence, there was no strategic plan other than the frame of the future perfect and the risk/reward scheme that accomplished it. Work was constructed imaginatively on an unfolding basis that continually rescoped the future perfect without reference to any original guiding design but with reference to a set of criteria on which the entire process would be judged. The project occurred despite the stillbirth of that strategic planning usually done by theoreticians, who make decisions early on based on minimal information, yet lock the process into an inevitable and unquestioned future. Instead, the people who had the greatest opportunity to alter the outcomes were the people who made up the strategy as they went along; normally they would be locked into protecting decisions already made for them through tactics that invariably lead to litigation. Rather than using detailed project scoping and planning to reduce high ambiguity, as is typical of construction (Stinchcombe 1985), the PALT project leaders sought to reduce it through creating a shared culture that enabled future perfect thinking to flourish in an imaginative process oriented to a broad range of imagined outcomes by which they would hold themselves accountable.

Future perfect thinking worked most smoothly where the planners had most control-that is, control of the technological and material context for future action. When external actors were empowered to question, achieving the future became more difficult. There were pitfalls in allowing for voice but not providing accompanying responsibility that increase the potential for a project to become hijacked. Future research should consider the empowerment of external stakeholders, where such stakeholders have not been involved in the accomplishment of the projected outcome. Further research 
on future perfect strategy needs to investigate the relationship between voice and responsibility. While project managers may adumbrate a strong culture, they should avoid being sucked in by its rhetoric and realize that it does not necessarily incorporate all stakeholders.

Schütz (1967) used some simple reflections on everyday life to make some complex analytical points about meaning; Weick $(1979,1995)$ built on this by introducing the idea of the future perfect into enactment, and enactment made its way into strategy. In this paper we have extended these ideas to illuminate the use of the future perfect as an alternative to the traditional approach to construction of contract packaging. The client selected its suppliers on the basis of cultural fit and technical competence rather than price; it then defined its needs in performance terms and empowered the team to develop the best solutions possible. In contrast, in the traditional approach strategic planning is finalized with limited information in advance of the project team being selected and the solution is locked in early, limiting creativity during delivery. It represented a shift of strategic decision making to the people who can make the difference-a reasoning that underlies the transformation of construction prefigured in this project. Consequently, we think that researchers should spend less time looking at strategic planning and more time researching everyday organizational life because, as the PALT realized, it is rather more in the detail that action unfolds and outcomes are produced-not so much in their a priori documentation and codification-which they could not have anyway. The project grew from just 28 pages, with no design and no clauses (other than an injunction to think in the future perfect and create a much cleaner Sydney Harbour) to a project that delivered what it set out to do: On time and only slightly over budget, it made Sydney Harbour sufficiently clear that in July 2002, in an ecologically symbolic representation of the success of the project, three 80-ton whales came into the harbour to frolic under the famous Sydney Harbour Bridge, with the equally famous Opera House behind them. ${ }^{9}$ In living memory, whales had never been this far into the Harbour before: The Olympic dream appeared to have been spectacularly realized.

\section{Acknowledgments}

The authors thank members of their research team, including Professor Peter Booth and Emma Bowyer. The authors also thank Dr. John Crawford for his valuable assistance, and Dr. Martin Kornberger and Adam Morgan. Financial support from the Australian Research Council through the ARC Large Grant and ARC Small Grants Scheme is gratefully acknowledged. Most of all, the authors would like to thank members of the NSTP Alliance-their openness and honesty during interviews and fieldwork over the last three years have proved to be the source of a rich and detailed data set. Finally, they would like to thank the three anonymous Organization Science reviewers for their valuable contribution to earlier drafts of this paper.

\section{Endnotes}

${ }^{1}$ We began research with questions about how quality was managed; we were sensitized to the importance of the future perfect from discussions monitored in "project alliance leadership team" (PALT) meetings. It should be clear that to label it as such was an analytic move rather than one embedded in the everyday experience of the subjects being researched. The concept was emergent from an exploration of the mechanisms of "collaborative quality."

${ }^{2}$ Successful completion of multiorganizational projects rarely involves a very high degree of coherence and unity of purpose and project, even at the management level (Flyvbjerg 2000). Conflict, ambiguity, and lack of common purpose have been much more evident, as past research has demonstrated (Higgin et al. 1966, Clegg 1975). In these organizational arrangements, despite the recourse to contractual tightness and strict surveillance, control has been extremely difficult to achieve (Stinchcombe 1985, pp. 25-27).

${ }^{3}$ The project client, Sydney Water, completed team selection and concurrently undertook the environmental impact statement (EIS) in record time in the three months between September and December 1997. The government approval for the project was given in late December and the alliance contract was signed in January 1998, leaving the team two years and nine months to complete the project. A five- to seven-year timespan would have been available under normal approaches to contracting. It was evident that normal contracting methodologies would not produce the Tunnel on time. While the time for completion was strictly stipulated at the outset, that it was to be ready for the Sydney 2000 Olympics, along with an approximate budget of (AU) 380 million dollars, were the only variables stipulated.

${ }^{4}$ It should be clear that the authors were at no stage consultants to the project.

${ }^{5}$ The detail of this "designer culture" is examined in more detail elsewhere (see Clegg et al. 2002).

${ }^{6}$ It should be stressed that this was only a part of our data collection strategy. Our initial aim in studying the Alliance was to study in detail how it managed collaborative quality. To this end, we collected qualitative data based on extensive interviews of personnel and observation of meetings and analysed those through open coding techniques assisted through qualitative analysis software. In the initial stages of the research, we identified and interviewed individuals in key positions within the alliance. A "snowball" effect led us to additional people who were information-rich respondents, familiar with the overall collaboration. In the course of the project, after a few months, when opposition to the project became vocal in the local media, we also interviewed key individuals who were affected by the project: government agencies, local councils, and community members-both those who supported and those who opposed the project. Twenty-two project team interviews were conducted (with another eight being with external stakeholders); the shortest interview took 90 minutes, the longest five hours. Semistructured interviews using an established interview protocol were designed to capture differing viewpoints on critical issues relating to colloborative quality. All those involved in data collection followed the same approach: All interviews were attended by a minimum of two and, in some cases, 
three principal researchers. Interviews were tape recorded and subsequently transcribed. Hence, rather than random sampling we used theoretical, purposive sampling (Cooper and Schindler 1998). Specifically, we used a variant called intensity sampling, a selection of "participants who are experiential experts and who are authorities about a particular experience" (Morse 1994, p. 228).

${ }^{7}$ The project was eventually fully commissioned some months later than the pre-Olympic date. Importantly, however, the project was certified as operationally available by the due date even though it was not completely finished. If the tunnel had been used at this stage, had the need transpired, it would have meant that some of the physical infrastructure that required decommissioning would have had to be sacrificed by being left in vaults off the tunnel.

${ }^{8}$ Over time, the list of issues and concerns on the agenda became longer and longer and it became clear that some issues were more noted than addressed, let alone resolved. They were mentioned as a concern at the outset, typically projected into the future, and then the next person's concerns were raised. When the list of issues and concerns became overwhelming, the project leaders, with some limited opposition, decided to delete the recurring item from the agenda, even though many of the issues were still to be resolved-especially those that concerned community relations and the social construction that key players in the community were placing on the issue of the tunnel-venting system as a potential source of pollution.

${ }^{9}$ Cynics might also want to note that the winter had been very dry, so little or no run-off would have occurred anyway.

\section{References}

Albrow, M. 1997. Do Organizations Have Feeling? Routledge, London, U.K.

Bandrowski, J. F. 1990. Taking creative leaps. Planning Rev. 18 34-38.

Bansal, P., K. Roth. 2000. Why companies go green: A model of ecological responsiveness. Acad. Management J. 43(4) 717-736.

Bavelas, J. B. 1973. Effects of the temporal context of information. Psych. Reports 32 695-698.

Boland, R. J. 1984. Sense-making in accounting data as a technique of organizational diagnosis. Management Sci. 30 868-882.

Buttery, E., L. Fulop, A. Buttery. 1999. Networks and interorganizational relations. L. Fulop, S. Linstead, eds. Management: A Critical Text. Macmillan, London, U.K., 414-463.

Clegg, S. R. 1975. Power, Rule and Domination: A Critical and Empirical Understanding of Power in Sociological Theory and Organizational Life. Routledge and Kegan Paul, London, U.K.

- 1989. Frameworks of Power. Sage, London, U.K. 1992. Contracts cause conflicts. P. Fenn, R. Gameson, eds. Construction Conflict Management and Resolution. E \& FN Spon, London, U.K., 128-144.

— T. S. Pitsis, T. Rura-Polley, M. Marosszeky. 2002. Governmentality matters: Designing an alliance culture of interorganizational collaboration for managing projects. Organ. Stud. 23(3) 317-337.

Cooper, D. R., P. S. Schindler. 1998. Business Research Methods, 6th ed. Irwin McGraw-Hill, Boston, MA.

Davis, S. M. 1987. Future Perfect. Addison-Wesley, Reading, MA.
Fineman, S. 2000. Emotion in Organizations. Sage Publications, London, U.K.

Flyvbjerg, B. 2000. Rationality and Power: Democracy in Practice. University of Chicago Press, Chicago, IL.

— M. S. Holm, S. Buhl. 2002. Understanding costs in public works projects: Error or lie? Amer. Planning Association 68(3) 279-295.

Garfinkel, H. 1967. Studies in Ethnomethodology. Prentice-Hall, Englewood Cliffs, NJ.

Gray, B. 1989. Collaborating: Finding Common Ground for Multiparty Problems. Jossey Bass, San Francisco, CA.

Higgin, G., N. Jessop, D. Bryant, J. Luckman, J. Stringer. 1966. Interdependence and Uncertainty: A Study of the Building Industry. Tavistock Publications, London, U.K.

Hitt, M. A. 1998. Twenty-first century organizations: Business firms, business schools and the academy. Acad. Management Rev. 23(2) 218-224.

Hogarth, R. 1987. Judgement and Choice: The Psychology of Decision, 2nd ed. John Wiley \& Sons, Chichester, U.K.

Keen, P. R., M. S. Scott-Morton. 1978. Decision Support Systems: An Organizational Perspective. Addison-Wesley, Reading, MA.

Koza, M. P., A. Y. Lewin. 1999. The co-evolution of strategic alliances. Organ. Sci. 9(3) 255-264.

Langlois, R. N. 1990. Bounded rationality and behavioralism: A clarification and critique. J. Institutional Theoret. Econom. 146(4) 691-695.

—, L. Csontos. 1993. Optimization, rule following, and the methodology of situational analysis. Uskali Mäki, Bo Gustafsson, Christian Knudsen, eds. Rationality, Institutions, and Economic Methodology. Routledge, London, U.K.

Lenz, R. T. 1987. Managing the evolution of the strategic planning process. Bus. Horizon 30(1) 34-39.

Leonard-Barton, D. 1992. Core capabilities and core rigidities: A paradox in managing new product development. Strategic Management J. 13 111-125.

Lukes, S. 1974. Power: A Radical View. Macmillan, London, U.K.

McHugh, P. 1967. Defining the Situation: The Organization of Meaning in Social Interaction. Bobs-Merrill, New York.

Mintzberg, H. 1990. Strategy formulation: Schools of thought. J. W. Frederickson, ed. Perspectives on Strategic Management. Harper-Collins, New York.

. 1994. The Rise and Fall of Strategic Planning. Free Press, New York.

Morse, J. M. 1994. Designing funded qualitative research. N. K. Denzin, Y. S. Lincoln, eds. Handbook of Qualitative Research. Sage, Thousand Oaks, CA, 220-235.

Ohmae, K. 1993. The rise of the region state. Foreign Affairs 72 $78-87$.

Petranker, J. 2000. Knowing the future: Toward a new temporality of change management. Paper presented at the annual meeting of the Academy of Management, Toronto, Canada.

Ringland, G. 1998. Scenario Planning: Managing for the Future. John Wiley \& Sons, Chichester, U.K.

Rollier, B., J. A. Turner. 1994. Planning forward by looking backward: Retrospective thinking in strategic decision making. Decision Sci. 25(2) 169-188. 
Rowe, H., R. Mason, K. Dickel. 1986. Strategic Management and Business Policy: A Methodological Approach. Addison-Wesley Publishing Co. Inc., Reading, MA.

Schilling, M. A. 1998. Technological lockout: An integrative model of the economic and strategic factors driving technology success and failure. Acad. Management Rev. 23 267-284.

Schütz, A. 1967. The Phenomenology of the Social World. Northwestern Press, Evanston, IL.

Stiles, R. M., J. M. Oliver. 1998. Anecdotes from alliancing. New Zealand Petroleum Conf. Proc. http://www.med.govt.nz/ crown_minerals/1998_pet_conference/stiles/index.html.

Stinchcombe, A. L. 1985. Project administration in the North Sea. A. L. Stinchcombe, C. A. Heimer, eds. Organization Theory and Project Management: Administering Uncertainty in Norwegian Offshore Oil. Norwegian University Press, Bergen, Norway, 25-118.
Strauss, A., J. Corbin. 1990. Basics of Qualitative Research: Grounded Theory Procedures and Techniques. Sage, London, U.K.

Van der Heijden, K. 1996. Scenarios: The Art of Strategic Conversation. John Wiley \& Sons, Chichester, U.K.

Weick, K. E. 1969. The Social Psychology of Organizing. AddisonWesley, Reading, MA.

. 1979. The Social Psychology of Organizing, 2nd ed. AddisonWesley, Reading, MA.

1995. Organizational Sensemaking. Sage, Thousand Oaks, 2000. Discussion piece presented at the annual meeting of the Academy of Management, Toronto, Canada.

Westley, F., H. Vredenburg. 1991. Strategic bridging: The collaboration between environmentalists and business in the marketing of green products. J. Appl. Behavioural Sci. 27(2) 65-90. 